\title{
Do Clinical Guidelines Still Make Sense? Yes.
}

\author{
Harold C. Sox, $M D^{1,2}$ \\ 'The Dartmouth Institute for Health Policy and Clinical Practice, Geisel School of Medicine at Dartmouth, Hanover, New Hampshire \\ ${ }^{2}$ The Patient-Centered Outcomes Research Institute, Washington, DC
}

Ann Fam Med 2014;200-201. doi: 10.1370/afm.1657.

$\mathrm{T}$ The subject of this Point / Counterpoint is the future of clinical practice guidelines. Does it still make sense to devote resources to creating them? Poor adherence is the principal argument against guidelines. Two articles in this issue show low rates of adherence to guidelines for statins and asthma, respectively. ${ }^{1,2}$ While its premise is true, the poor adherence argument ignores the good that guidelines do. First, they represent a profession's best efforts to define its standard of practice. Second, health insurance companies use guidelines to help decide their coverage policies. Third, guidelines are the basis for practice measures, which do influence clinical practice. ${ }^{3}$ Fourth, the systematic reviews that serve as the basis for practice guidelines are a public good.

For these reasons, although practice guidelines have a bright future, they need fixing. I address 3 questions. How can we increase public trust in guidelines? How can we make guidelines more transparent to the public? What is the role of practice guidelines in the era of shared decision making?

What is a practice guideline? The 2010 Institute of Medicine (IOM) study entitled "Practice Guidelines That We Can Trust" defined them as follows:

"Clinical practice guidelines are statements that include recommendations intended to optimize patient care that are informed by a systematic review of evidence and an assessment of the benefits and harms of alternative care options."

This definition states the aim of guidelines - to optimize care-and identifies 2 process elements as so fundamental that a guideline without them is not to be trusted. The first, a systematic review, is an unbiased

Conflicts of interest: authors report none.

\section{CORRESPONDING AUTHOR}

Harold C. Sox, MD

31 Faraway Lane

West Lebanon, $\mathrm{NH}$

hsox@comcast.net method for describing a body of evidence. The second, the difference between benefits and harms (the net benefit), is a strong rationale for choosing the option with the largest net benefit.

\section{PUBLIC TRUST}

Guideline developers must protect their position of public trust by adopting strong policies on managing conflicts of interest. When people step into the role of guideline panelist, making a recommendation that is true to the evidence must become their primary interest. A conflict of interest occurs when a secondary interest could lead to a recommendation that betrays the public's trust. According to the IOM, conflicts of interest should be published, panelists with conflicts should be balanced by panelists without conflicts, and conflicted panelists should recuse themselves from discussion and voting on topics when they are conflicted. ${ }^{4}$

\section{TRANSPARENCY ABOUT BENEFITS AND HARMS}

With strong policies on conflict of interest and systematic reviews, a guidelines program has 2 key characteristics. The third-identifying recommendations with the best trade-off between harms and benefitscan be the most difficult to achieve. Consider the choice between Recommendation A and Recommendation $B$, both based on the same body of evidence. The choice is easy if Recommendation A has larger benefits and smaller harms. But suppose that Recommendation A has larger benefits and larger harms. The choice now depends on the guideline panelists' judgment of the trade-off between the benefits and the harms of each recommendation. Because the measures of harms (eg, incidence of adverse effects) and benefits (eg, cure rate) differ, the guideline panelists' judgment about the net benefit of Recommendations A and B is subjective and therefore difficult to explain.

Estimating net benefit would be more transparent 
if the measure of harms and benefits was the same. Since harms decrease lifespan and the quality of life, and benefits increase both, a measure that combined lifespan and quality of life could serve as a measure of benefits and harms.

The investigators of the European Randomized Study of Prostate Cancer Screening (PSA) used a decision model to project the quality-adjusted life-years gained or lost from PSA screening. ${ }^{5}$ The model showed that men who are very concerned about losing sexual and voiding function would lose quality-adjusted lifeyears from screening. Other men would gain qualityadjusted life-years. A guideline based on this study would recommend a discussion about the importance the patient places on these functions rather than recommending never screening or always screening. This study is an important model for communicating the scientific rationale for a clinical recommendation. The article had a clear explanation of how the authors calculated the quality-adjusted life-years gained or lost from screening, treatment, and response to treatment. ${ }^{5} \mathrm{~A}$ guideline based on this study would have a transparent rationale for recommending shared decision making. ${ }^{6}$ Any other recommendation would be difficult to sustain.

\section{SHARED DECISION MAKING AND PRACTICE GUIDELINES}

In shared decision making, a patient uses a decision aid to prepare for a discussion with his or her clinician. The decision aid describes the outcome states that might occur and the likelihood that they will occur. The patient and clinician then discuss these possible outcomes and how the patient feels about them. The patient might assert a preference, or the clinician might offer a recommendation based upon the patient's expressed values and the likelihood that the patient will experience the outcome states of greatest concern.

Knowledge of how a patient might use a decision aid offers some insight about the limitations of guidelines in the era of shared decision making. Decision aids usually include a summary table describing possible interventions, the outcomes that might occur, and the likelihood of these outcomes with each interven- tion. The patient may learn enough from this table to make a choice. In principle, a decision made by a fully informed patient is the best choice for that patient. ${ }^{7} \mathrm{~A}$ guideline committee's subjective judgment of the balance of harms and benefits will not necessarily apply to that patient, but the patient's assessment of the same evidence will apply. From this example, we learn that a guideline based on group judgement about net benefits may be wrong for an individual patient.

Shared decision making is unlikely to displace practice guidelines. It is just right for a preferencesensitive decision, in which some patients gain quality-adjusted life-years and others lose them. It is unnecessary for preference-insensitive decisions, in which everyone will gain quality-adjusted life-years or everyone will lose them. These cases will warrant a strong recommendation, which is the province of practice guidelines. Most likely, future health care will need practice guidelines for some decisions and shared decision making for others.

To read or post commentaries in response to this article, see it online at http://www.annfammed.org/content/12/3/200.

Key words: clinical practice guidelines; shared decision making

Submitted April 1, 2014; accepted April 1, 2014.

\section{References}

1. Johansen ME, Green LA, Sen A, Kircher S, Richardson CR. Cardiovascular risk and statin use in the United States. Ann Fam Med. 2014;12(3):215-223.

2. Mold JW, Fox C, Wisniewski A, et al. Implementing asthma guidelines using practice facilitation and local learning collaboratives: a randomized controlled trial. Ann Fam Med. 2014;12(3):233-240.

3. Jha AK, Perlin JB, Kizer KW, Dudley RA. Effect of the transformation of the Veterans Affairs Health Care System on the quality of care. N Engl J Med. 2003;348(22):2218-2227.

4. Institute of Medicine. Clinical Practice Guidelines We Can Trust. Washington DC: National Academies Press; 2011.

5. Heijnsdijk EAM, Wever EM, Auvinen A, et al. Quality-of-life effects of prostate-specific antigen screening. N Engl J Med. 2012;367(7):595-605.

6. Sox HC. Quality of life and guidelines for PSA screening. N Engl J Med. 2012;367(7):669-671.

7. Sox HC, Greenfield S. Quality of care-how good is good enough? JAMA. 2010;303(23):2403-2404. 